\title{
Using the lens of science capital to capture and explore children's attitudes toward science in an informal making-based space
}

\author{
Dimitra Christidou, Sofia Papavlasopoulou and Michail Giannakos \\ Department of Computer Science, \\ Norwegian University of Science and Technology, Trondheim, Norway
}

\begin{abstract}
Purpose - Governments and organizations worldwide are concerned over the declining number of young people choosing to study Science, Technology, Engineering and Mathematics (STEM), especially after the age of 16. Research has foregrounded that students with positive attitudes toward science are more likely to find it relevant and aspire to a science career. This study aims to understand the factors shaping students' attitudes as these are pivotal in promoting science learning.
\end{abstract}

Design/methodology/approach - This study uses the framework of science capital to understand what shapes young people's engagement with or resistance to science. The authors conducted four Computational Thinking making-based workshops with 106 children aged 15-16 years, of which 58 filled in a questionnaire and 22 were interviewed. Statistical and content analyses were performed respectively.

Findings - The results indicate that children who are more exposed to science-related activities and contexts are more likely to have higher self-efficacy, and that those with higher prior coding experience scored higher in their self-efficacy and science capital. Six themes emerged from the content analysis, highlighting the diverse factors shaping students' attitudes, such as teaching methods, stereotypes and the degree of difficulty encountered while engaging with science in and out of school.

Originality/value - By combining qualitative and quantitative methods with the use of science capital, the authors found a number of aspects of the school experience that shape students' attitudes to science learning in and out of school, as well as their science career aspirations.

Keywords Making, Informal learning, Science capital, Attitudes, Self-efficacy

Paper type Research paper

(C) Dimitra Christidou, Sofia Papavlasopoulou and Michail Giannakos. Published by Emerald Publishing Limited. This article is published under the Creative Commons Attribution (CC BY 4.0) licence. Anyone may reproduce, distribute, translate and create derivative works of this article (for both commercial and non-commercial purposes), subject to full attribution to the original publication and authors. The full terms of this licence maybe seen at http://creativecommons.org/licences/by/4.0/legalcode

The authors are grateful to the students, teachers and parents who supported this research. The authors would like to thank Kshitij Sharma for his valuable contribution to the quantitative analysis. This work is supported by the "Learning science the fun and creative way: coding, making, and play as vehicles for informal science learning in the 21st century" project (COMnPLAY-Science project), under the European Commission's Horizon 2020 SwafS-11-2017 Program (Project Number: 787476). The authors would like to thank the partners of the COMnPLAY-Science project (https:// comnplayscience.eu/) who supported the formation of the research instruments and tools (see the COMnPLAY SCIENCE, 2021 report and the Appendices of the paper) and informed this work through ongoing discussions.

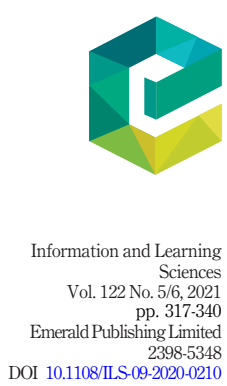


ILS

$122,5 / 6$

\section{Introduction}

Many governments and organizations worldwide are highly concerned about the declining number of young people choosing to study Science, Technology, Engineering and Mathematics (STEM), especially after the age of 16 [Barton et al, 2017; National Science Foundation (NSF), 2019]. Previous research has highlighted that learning opportunities organized according to project-based and learner-centered approaches encourage and sustain motivation and engagement in STEM (Vossoughi and Bevan, 2014). Such activities provide learning opportunities for young adults and allow them to express their creativity through creating something, (re)building prototypes, designing, coding and debugging (Giannakos and Jaccheri, 2018; Papert, 1980; Vossoughi and Bevan, 2014).

To tackle the aforementioned declining tendency, there has been a universal rise of science-related activities and communities in and out of school (Halverson and Sheridan, 2014; Papavlasopoulou et al., 2017; Peppler et al., 2016; Vossoughi and Bevan, 2014), with Coding and Computational Thinking (CT) being vital parts of this movement (Kafai et al., 2014; Kafai and Peppler, 2014). In designing such activities, educators need to consider participants' attitudes, dispositions and background to understand the factors shaping their engagement with and potential resistance to science in both formal and informal science learning settings, with the aim of designing better activities and learning scenarios.

For this study, we implemented four workshops focusing on CT and coding with more than 100 children at an informal making-based space in Norway. We employed the lens of science capital (Archer et al., 2015) as a way of capturing and exploring young adults' science-related knowledge, attitudes, experiences and social contacts (Godec et al., 2017). The design and implementation of the study aimed to answer the following questions:

Q1. What are students' attitudes, beliefs and dispositions toward science learning in and outside school, in the context of CT and coding activities in informal making-based spaces?

Q2. Which factors are foregrounded by the students as important or not in shaping their attitudes to science?

We combined qualitative and quantitative methods and tools, and we collected data through 58 questionnaires and 22 semi-structured interviews, which we analyzed statistically and through content analysis, respectively.

In this paper, we discuss the literature relevant to science attitudes and present science capital as a lens to explore students' perceptions and attitudes toward science. We then detail our study's setting, method and data collection process. Next, we describe our analytical approach and the findings based on the analysis of the quantitative and qualitative data set, after which we present a thorough discussion, potential contributions to research and practice and the limitations identified in our approach.

\section{Attitudes toward science}

Numerous studies have explored students' attitudes toward science (George, 2006; Regan and DeWitt, 2015) and indicated a link between positive attitudes toward science and students' expression of interest in pursuing a scientific career (Bonner and Dorneich, 2016; George, 2006; Osborne et al., 2003; Tytler and Osborne, 2012). Students' attitudes seem to be positively affected through their engagement in opportunities entailing "experimentation" or "accomplishment" and negatively through opportunities "wanting involvement" or "giving instructions" (Chu et al., 2017a). Indeed, activities with playful elements, such as sketching, making a game and using a $3 \mathrm{D}$ printer, encourage engagement, which in turn results in an overall sustained enjoyment of science (Martin, 2015; Sheridan et al., 2014). Additionally, they seem to influence positively students' confidence in problem solving (Vossoughi and Bevan, 2014) and their self-efficacy 
(Chu et al., 2017b; Schlegel et al., 2019) - that is, the belief in one's capacity to succeed in tasks in science-related contexts (Bandura, 1977, 1997).

Research on self-efficacy and the use of Information and Communication Technology (ICT)

Lens of science indicates a positive relationship between self-efficacy in ICT and the use of ICT (Yang and Cheng, 2009). Students, especially in making and coding contexts, both construct their own knowledge and develop their self-efficacy, which is a strong predictor of STEM-related career or college aspirations (Bandura et al., 2001; Wang, 2013). Nonetheless, students' attitudes to STEM careers are under development during their primary and secondary grades and tend to capital stabilize during their secondary years (Bennett and Hogarth, 2009; Osborne et al., 2003).

In this paper, we explore the science attitudes of young adults (15-16 years old) in the context of making and coding activities. We define attitudes as "the feelings, beliefs and values held about an object that may be the enterprise of science, school science, the impact of science on society or scientists themselves" (Osborne et al., 2003, p. 1050). To explore their attitudes, we use the lens of science capital (Archer et al., 2015; DeWitt et al., 2016), which serves as "a way of encapsulating all the science-related knowledge, attitudes, experiences and social contacts that an individual may have" (Godec et al., 2017, p. 5). Specifically, by adopting the science capital lens, we explore the following eight dimensions of students' science attitudes:

(1) students' scientific literacy;

(2) science-related attitudes, values and dispositions;

(3) knowledge about the transferability of science;

(4) science media consumption;

(5) participation in out-of-school science learning contexts;

(6) family science skills, knowledge and qualifications;

(7) knowing people in science-related roles; and

(8) talking about science in everyday life with key people in their lives, such as friends, siblings, parents, neighbors and community members.

By taking all these aspects into consideration, science capital helps us understand what shapes young people's engagement with and potential resistance to science while aiming at broadening what counts as doing science in classrooms (Godec et al., 2017).

This paper is one of the few that combines qualitative and quantitative methods with science capital to investigate aspects that shape students' attitudes and aspirations toward science learning in and out of school. We explore the case of Norway because recent research has indicated that the more "gender equal" a country is, the larger the gender gap in STEM education and careers (Stoet and Geary, 2018).

\section{Methodology}

The study took place at Kodeløypa ("the path toward coding" in English), located at the Department of Computer Science at the Norwegian University of Science and Technology in Trondheim, Norway. Secondary school students from the Trøndelag region can visit Kodeløypa and learn about programming and coding through making and creating an artifact.

\subsection{Participants}

A total of 106 students from two regional schools (three school classes from one school and one from the other) participated in four making-based coding workshops during January and February 2020. All students were attending 10th grade. Nevertheless, the entailed 


\section{ILS}

$122,5 / 6$

320

significant advantages of the practicalities of the study (e.g. coordination with one school) might impact the selection and diversity of the sample.

After being granted ethical approval by the Norwegian Center for Research Data, one of the researchers contacted the teachers and asked them to send an information letter to the parents/legal guardians and a consent form for them to sign. Out of the 106 students, we received signed consent from the guardians/carers of 58 of them (28 boys and 30 girls; 50 participants were aged 15 , and 8 were 16 years old).

\subsection{Workshops}

Each workshop had two sections:

(1) interaction with the robots; and

(2) creation of games. Four workshops were held, each mediated by four facilitators who observed and helped one or two teams each. Students could decide how to split into teams and on their roles.

Depending on the size of each class, students split into teams of two or three, sharing one desktop PC or laptop, and an animal-shaped robot, made of recycled materials, with electrical components, small motors and LED lights on it (Figure 1). During the workshop, students used the Scratch and Scratch for Arduino (S4A) software, and Arduino, which is a small micro-controller, as the hardware. S4A is a way to "talk" to the Arduino via Scratch.

During the first section of the workshop, each student was handed a worksheet and a printed tutorial with instructions and images showing how to control the robots with S4A (Figure 2). They then accomplished a series of simple loops using S4A to control the robots with Arduino, moving them in specific ways (e.g. the snake moves its tongue) and turning their LED lights on and off. The students were then instructed to fill in the worksheet, answering questions about the exact place and the number of sensors and lights on the robots assigned to each group. This section lasted between 45 and $90 \mathrm{~min}$, and it was followed by a short break before section two commenced.

During the second section, which lasted approximately three hours, the students developed a game using Scratch by following a paper-based tutorial with instructions, containing text explanations of basic CT concepts and possible loops, as well as examples and visualizations to help them ideate their own game (Figure 3). Students were advised to concentrate on understanding the idea of the game, discuss it with their team members, and then create a draft storyboard. To accelerate their progress, they were given already existing

Figure 1.

A group of two girls working on the development of their game

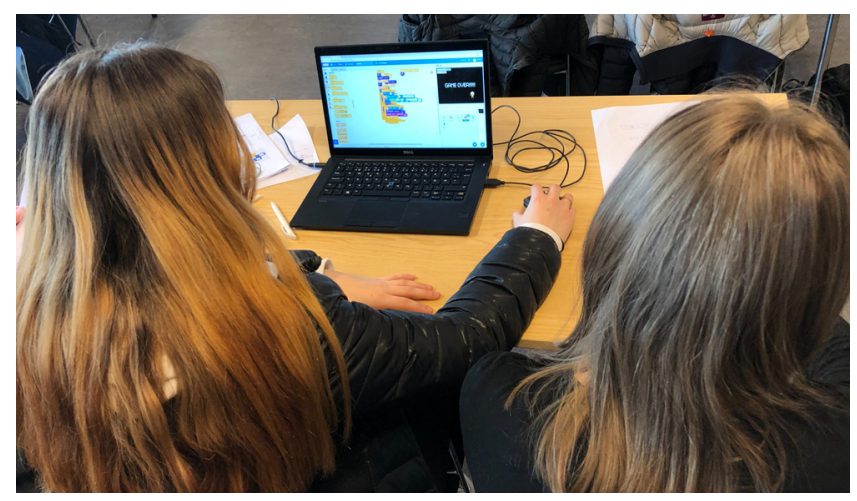


game characters and easy loops. They then used iterative coding and testing to develop their own game, which they shared with the other teams.

Lens of science capital

\subsection{Data collection}

At the end of each workshop, we collected data from the 58 participants through a paperbased questionnaire in Norwegian (Appendix 1, translated English version). The questionnaire comprised 25 questions: five on students' demographics and their previous experience of coding; eight on their self-efficacy in science-related subjects following Nietfeld et al. (2006); and 12 on their science capital based on DeWitt et al. (2016) and the EU project COMnPLAY (see Appendix J of COMnPLAY Science, 2021)). Our aim was to investigate any potential differences, relations, correlations regarding students' science capital, self-efficacy while collecting information about their gender and prior knowledge and experience with coding.

Additionally, we conducted semi-structured interviews with 22 randomly selected students from the 58 in our sample, of which 18 interviews were in Norwegian and were conducted by the facilitators, and four were in English and conducted by one of the authors. For the latter, both the student and the teacher confirmed the child's fluency in English. We followed an interview protocol with 27 questions (Appendix 2) on student attitudes, engagement and participation in STEM subjects and student attitudes, engagement and participation in the coding workshop, with the possibility of using unscheduled prompts to

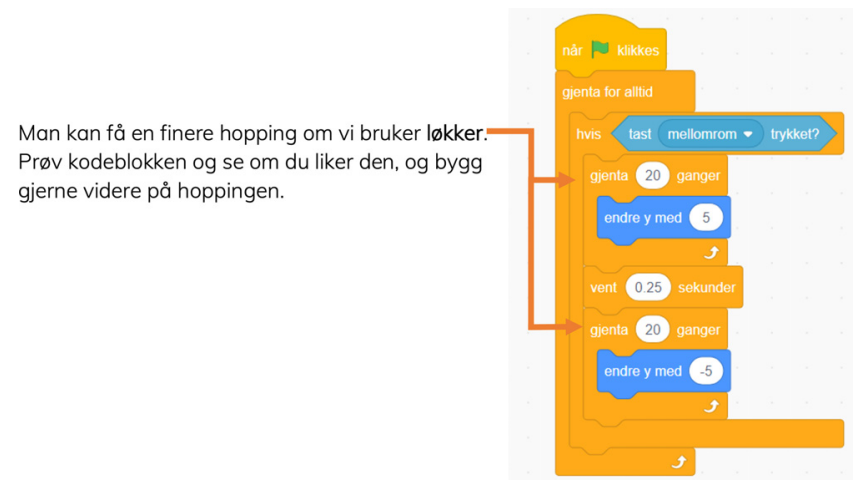

Figure 2.

Example of the robots' tutorial (left) and the respective robot that students interacted with

\section{REAKSJON}
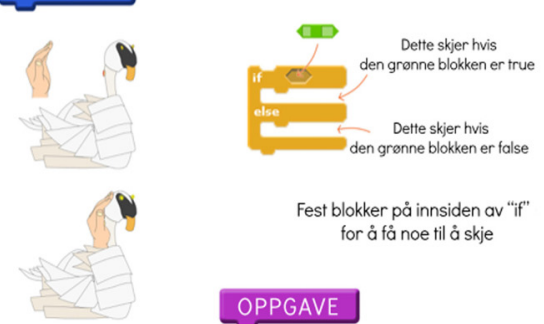

Fest blokker på innsiden av "if" for å fả noe til ả skje

\section{OPPGAVE}

Fả roboten til à lyse når dere holder hånda over lyssensoren Bruk forever-blokken rundt "if" for at Scratch skal sjekke verdien fil sensoren hele tiden

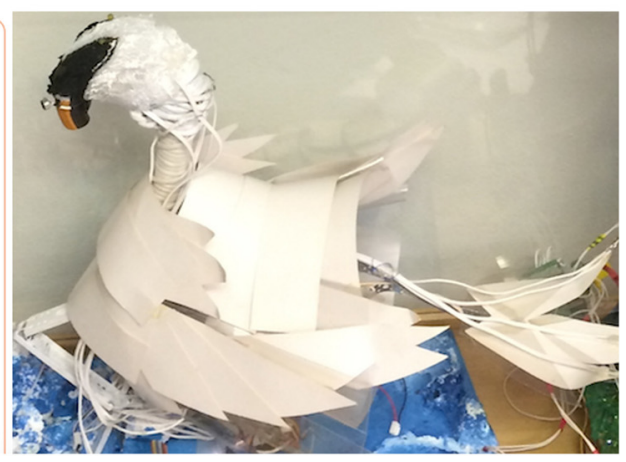

Figure 3.

Example of the paper tutorial with instructions on how to use Scratch 


\section{ILS}

$122,5 / 6$

\section{2}

Figure 4.

(a) Students' science capital scores for low and high experienced students in coding (b) Students' selfefficacy for low and high experienced students in coding

encourage participants' elaboration. All interviews were tape-recorded, with the recordings totaling approximately four hours $(\min =5 \mathrm{~min}, \max =20 \mathrm{~min}$ and $33 \mathrm{~s}$ ).

\subsection{Analyses}

We used statistical analysis for the quantitative data and thematic analysis for the qualitative data set. Specifically, for the quantitative data, we calculated the scores of science capital for the students based on the coding scheme in Appendix 1. Moreover, we used analysis of variance (ANOVA) to examine the effect of gender, previous coding experience and previous attendance on students' science capital and self-efficacy (Figure 4 and Table 1). For each of the questions posed in the questionnaire, we provide its descriptive statistics (Appendix 3).

For the qualitative data, we started the analysis as soon as we collected the interviews by translating the 18 Norwegian interviews into English and transcribing all 22 interviews word for word (verbatim transcription). All transcripts were uploaded on the NVivo 12 qualitative software. We employed thematic analysis (Clarke et al., 2019), consisting of a form of pattern recognition within the data during which emerging themes become the categories for analysis. Using an iterative and reflexive process, each member of the research team carefully read the transcripts line by line and applied a paraphrase or label (a "code") that describes what they interpreted in the passage as important (Cohen et al., 2011). After coding several transcripts, the team compared the coding scheme each had applied by going over the transcripts line by line. In cases where interpretations differed, we reached an agreement via further study and discussion of the text. Codes were grouped together into categories (a "tree"), and these categories were then clearly defined and formed our working analytical framework. After several iterations, we reached data saturation as no additional codes emerged. We then applied the final coding scheme on the data set and interpreted the data.

\section{Results}

\subsection{Results extracted from the quantitative analysis}

The participants in the four workshops were 28 boys (48.3\%) and 30 girls (51.7\%) attending 10th grade in Norway (15 or 16 years old; mean $=15.4, \mathrm{SD}=0.34$ ). Based on the descriptive results of the questions (Appendix 1), students' science capital scores fell between -1.05 and

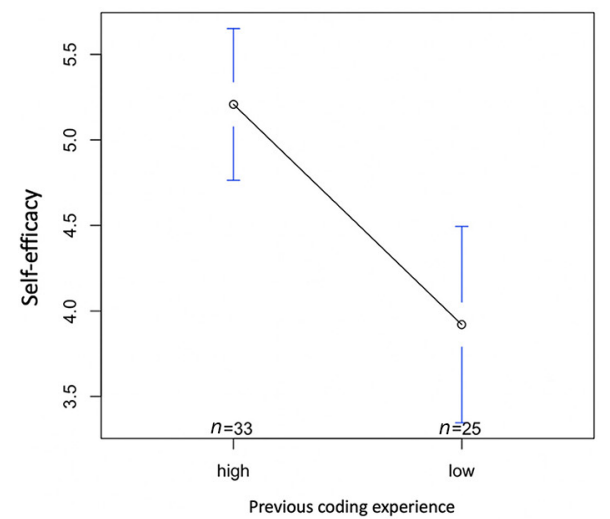

(a)

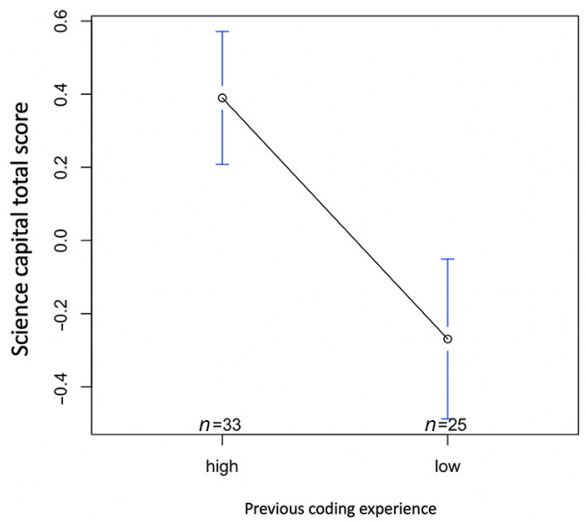

(b) 
1.40 (mean $=0.10, \mathrm{SD}=0.61$, theoretical minimum $=-2$, theoretical maximum $=2$ ). For Lens of science conceptual use, we grouped them into three groups:

(1) low science capital ranging from -2 to- -0.67 (seven students, $12.06 \%$ );

(2) medium ranging from -0.67 to 0.67 (39 students, $67.24 \%$ ); and

(3) high ranging from 0.67 to 2 (12 students, $20.68 \%$ ).

We then examined students' self-efficacy as a construct of eight different items answered on a seven-point Likert scale (Appendix 1). Cronbach's test was conducted to examine the reliability, and its results showed acceptable internal consistency $(\mathrm{CR}=0.92)$. Consequently, factorial analysis, with principal components and varimax rotation, was carried out to test the construct's unidimensionality and validity. All items exhibited factor loadings that were higher than 0.7 , with no cross-construct loadings, indicating good discriminant validity. Consequently, it is possible to use a sole factor to represent each theoretical construct. Based on the median and the histogram of the variable/construct of self-efficacy, we divided the sample into two categories: those students with low self-efficacy (less than 4.57) and those with high (more than 4.57). Of the 58 students in our sample, 28 had high self-efficacy $(48.3 \%)$ and 30 low $(51.7 \%)$. Based on Pearson's correlation coefficient, science capital score and self-efficacy are highly correlated $(\mathrm{r}(56)=0,73 ; \mathrm{p}=0.000001)$.

To explore students' prior coding experience and previous participation in coding activities, we looked closely at the questions "Did you have any idea about programming before this workshop?" (hereafter referred to as prior coding experience) and "how many workshops (e.g., on Scratch, Alice, Lego Robots, Python) have you participated in before?" (hereafter referred to as a previous attendance) (Appendix 1). Based on their answers, we formed groups with low ( 1 on the Likert scale, $\mathrm{n}=25$ ) and high ( $2-7$ on the Likert scale, $\mathrm{n}=$ 33) prior coding experience; and no previous attendance (no prior workshop, $\mathrm{n}=37$ ) and previous attendance (one or more workshops, $\mathrm{n}=21$ ). There were almost twice as many students reporting that they had participated in no workshops (37 students, 63.8\%) as students who had participated in one or more (21 students, $36.2 \%$ ).

To identify the extent to which gender, prior coding experience and previous attendance affected students' self-efficacy and science capital, we performed an ANOVA with selfefficacy and the science capital score as dependent variables and gender (boys and girls),

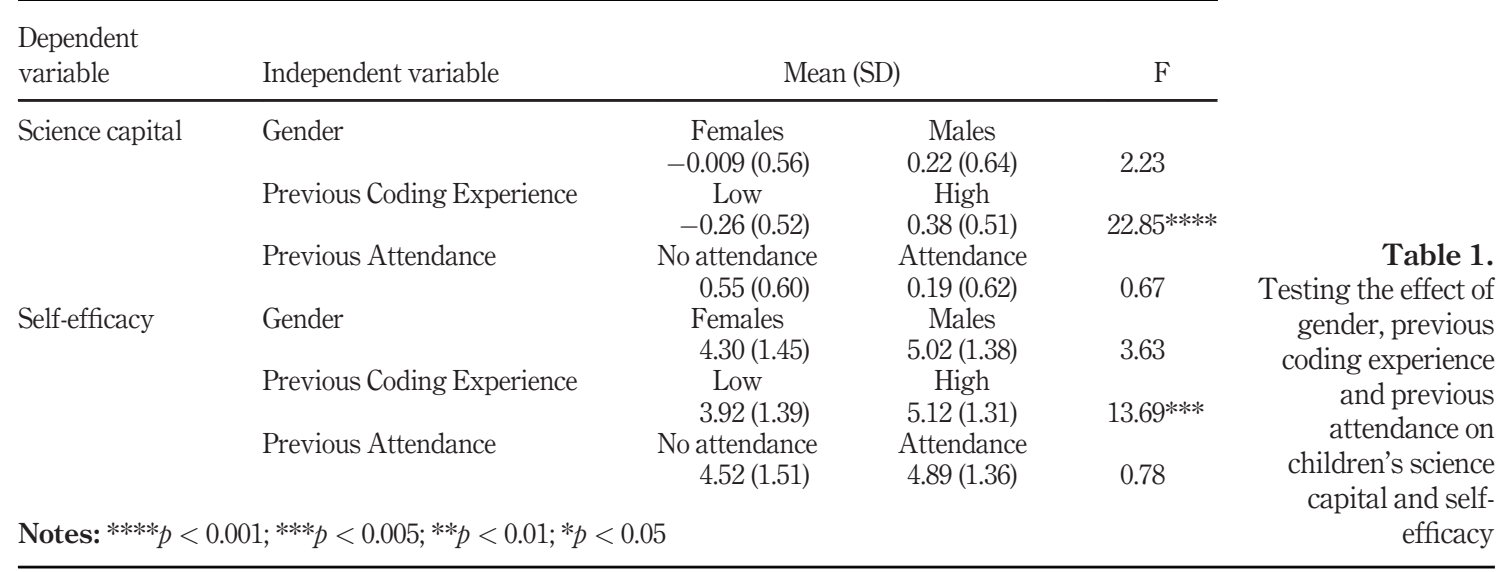


ILS $122,5 / 6$

previous coding experience (low/high) and previous attendance (attendance/no attendance) as independent variables. The results show that there is no significant effect of gender on self-efficacy $(F(1,57)=3.63 ; p=0.06)$ or on science capital $(F(1,57)=2.23 ; p=0.14)$. There is no significant effect of students' previous attendance on self-efficacy $(F(1,57)=0.78$; $p=$ $0.37)$ or on science capital $(\mathrm{F}(1,57)=0.67 ; \mathrm{p}=0.41)$. However, there is a significant effect of students' previous coding experience on self-efficacy $(\mathrm{F}(1,57)=13.69 ; \mathrm{p}=0.0004)$ and on science capital $(\mathrm{F}(1,57)=22.85 ; \mathrm{p}=0.00001)$ (Figure 4) (Table 1). Therefore, self-efficacy and science capital were significantly higher for students who had high previous coding experience.

\subsection{Science-related attitudes: results from the qualitative analysis}

In this section, we detail the themes emerging from the analysis through excerpts from the interviews. When analyzing the data set, we categorized the attitudes students reported as positive, negative and neutral. This categorization allowed us to identify their overall attitudes, which we then explored in detail.

Most students reported positive attitudes to science, describing it as "fun" because "you learn something new", especially when working on experiments in the laboratories. Students positively valued opportunities for hands-on learning in the labs, reflecting on how experiments allowed them to "make new discoveries" (\#13) and have "some action - when there is a little flame involved - when a thing goes inside things and reactions happen" (\#09). Several students also reported negative attitudes toward science, mainly due to the perceived difficulty when attending science classes at school ("hard, boring and complicated", \#07; "hard to learn it", \#11). This perceived difficulty seemed to trigger confusion and spoil the fun, which is an aspect of science learning that students valued positively ("when I don't understand it, it won't be so fun", \#09). Additionally, a few students reported neutral attitudes, thinking of science learning as "okay [...]. It is not the most fun I know of, but it is ok" (\#18).

To explore those attitudes in depth, we coded the factors shaping them as reported in the students' interviews as follows.

A. Perception of science/scientists. When asked to describe what came to mind when they heard the word "science", the majority of the students named school subjects such as biology, physics, math, chemistry and natural sciences, including geology and geography. A few named school practices instead, such as "sitting and doing tasks" (\#20), and others offered more descriptive accounts. These descriptive accounts mainly related either to the difficulty encountered when doing science ("difficult and complicated" [\#22]; "hard" [\#07]) or science being "the future and the past" (\#01), "new knowledge and understand the world better" (\#17) and "trying to find new things to help us out in everyday life and try to learn new stuff” (\#05).

Similarly, students reported that they thought of scientists as "people who explore, discover and find answers to problems" and "people who are smart and curious" (\#13) and who try "to solve different questions" (\#02) and "try to discover new things" (\#15; \#16; \#19; \#24; \#03) that "can help humanity" (\#17; \#01). All these descriptions hint at scientists being perceived by the students as "people who want to find answers" (\#22). Several thought of scientists in terms of performing laboratory work and experiments, and others thought of them as wearing white coats, "mixing different liquids together and seeing what kind of reaction happens" (\#14). This is a stereotypical image of a scientist that mostly comes from images seen on television and in the movies, which often feeds into negative attitudes about science being "not for them". Students' perceptions of science and scientists appeared to influence how they imagined themselves (or not) in a science-related profession. 
B. Perception of teacher and teaching method. Students very often linked their attitudes toward science to the perceptions of the teacher: "it depends on the teacher. Last year we had a different teacher in math that was horrible, but now we have a really good one" (\#13) and "it's a little fun because of the teacher we have" (\#09). Their perception of the teacher is based mainly on how the teacher teaches; for example, as someone who "talks and shows things on a screen" (\#05) but also someone who "stands up, shows us on the board and brings some humor" (\#09). These quotes illustrate the importance of teaching methods in the shaping of students' attitudes toward science; hands-on learning, variety of methods and creativity in teaching contribute to students' positive experience during science learning, which in turn informs their overall positive attitudes toward science.

Specifically, students regularly differentiated between negative experiences of "being taught while sitting and writing" and positive experiences related to "doing things at the lab". When the teaching method involves purely instruction, students tend to lose interest and engagement ("when we are just sitting in the classroom and writing and doing tasks, I get a little bored" [\#12]; "theory lessons, where we sit and write, are not always fun" [\#05]; and "formulas and things like that can be a bit boring" [\#18]). By contrast, "doing things at the lab" offers students opportunities to "get to use your hands instead of just writing" (\#17) and to "do some research, because we get to do something else than just sitting and writing" (\#18). Overall, students expressed their preference for hands-on learning as it facilitates their learning by demonstrating phenomena ("if we could have shown it, would be much easier to learn about it" [\#12]) while also offering them practical experience of those phenomena through the experiments they perform using their own hands: "the lab hours are very fun, since we get to try some of what we should know" (\#05) and "if you can feel and do something [...] it is much better than reading about somebody else doing it" (\#13). Similarly, the importance of diversity in teaching was implied when students talked about performing the same tasks repeatedly as a factor triggering disengagement and boredom: "if my teacher tells me to do like 500 mathematical problems, that could get boring after like the first 10" (\#01) and "by writing on a blackboard, I get that in the book, but I don't remember it. [...] I can't remember everything. I'm just writing down in the book" (\#09). However, when "one sits there not only to learn and write off the board [. . .] It becomes a little more fun and fun to learn about it. [....]I remember a little more" (\#09).

C. The value of science studies: importance of science. Under this category, we grouped those codes related to students' perceptions about the role and value of science as well as their beliefs about themselves into essential value and no value. Essential value refers to students recognizing the value of science as being relevant and useful in everyday life, and as contributing to problem-solving ability, scientific thinking and the development of a future career. Students closely linked the value of science to understanding the present and discovering things that will be helpful in the future; for example, "if we had not learned about it, not as many could, in a way, found out about, for example, global warming now" (\#11) and "when I hear the word science [... I I think of both the future and the past. I think of using the past to strengthen the future. [. . .] I believe that we can use all types of science, like chemistry and other stuff, to help humanity get to different types of goals. If it is space travel or medicine, just a useful way to support humans in their existence" (\#01).

No value refers to the students' belief that science is irrelevant and insignificant for them. For example, some stated that it was "not for me" (\#18; \#21) and "I am not interested enough" (\#18; \#09), whereas others mentioned that "I think studying science would be great, but I don't think it is something I will continue doing further in my life" (\#03/04).

D. Pursuing a career as a scientist. Several students were highly interested in science learning but did not feel confident about their ability to successfully engage with science: "I 
ILS

$122,5 / 6$

believe I could become a scientist if I really want to put in the time for it. I do. And there are a lot of topics in science that are cool to learn about and have the knowledge about" (\#01). The need to "put in more time" also becomes grounded when the same student reflected on how well they were doing at school ("I believe I am in the middle. I know basic stuff, but there are also things I get wrong. With learning what I did wrong, I can build up so I can move forward" \#01) and on their participation in activities out of school ("I like to think a lot. Even when I am home, I think a lot about science stuff, especially space. I really like space. It is just the thought of endless opportunities. And how all of it came together and how one big explosion could make life. I believe it's cool" \#01). These insights indicate the importance of intrinsic motivation and interest and its potential to, sometimes, overcome the lack of confidence in deciding to pursue a science career.

Several students reported that despite doing well in science at school, they were not sure that being a scientist and studying science was something for them: "I don't know if it is for me, but it sounds interesting" (\#21); "I think studying science would be great, but I don't think it is something I will continue doing further in my life" (\#3); "I think it could be a bit boring for me. I am more of a practical person. But there can be parts of science that can be practical" (\#21).

E. Knowledge about the transferability of science. All instances in which students reflected on their understanding of the utility and broad application of scientific skills, knowledge and qualifications fell under this code. Vivid and broad accounts such as "science is everywhere" (\#02; \#07), "it is probably smart to study something within technology, because it is the future" (\#11), and "the future is computers and artificial intelligence" hint at students' awareness of the promising development of technology in today's society and the value in engaging with science. Its contribution is more fleshed out through accounts such as "to improve the world" (\#17); "to develop society" (\#02); "to get the answer to why things are the way they are" (\#14); "because it helps you understand how things work. For me that is kind of like a meaning to life. Understanding what's going on everywhere" (\#01); and "if you can understand science, you can also understand more about what's around you” (\#02).

$F$. Science literacy. Under this category, we merged all instances of participants referring to sources informing their attitudes to science. Students named school and their time in laboratories as their main sources of scientific literacy, followed by talking about science in everyday life with others, and participating in out-of-school activities. Their everyday discussions with members of their families were exemplified by attempts to become more environmentally friendly ("we talk about plastic at home, because we try to use less plastic at home so we can help the Earth and try to be better examples" [\#12]) and when talking about food ("our family can sit down to discuss a type of dish and end up discussing science [naturfag in Norwegian] and that kind of science (realfag in Norwegian)" [\#11]).

A small number of students referred to their participation in out-of-school science learning contexts, such as going hiking and fishing, as activities during which they learned about science. Several of them named TV, movies and television series and reading books and magazines as the main media through which they were exposed to images of science and scientists. Watching television, including movies and television series or programs such as the Discovery channel and MythBusters, was named on many occasions as the main source of information about what science is and what a scientist looks alike. Three of them mentioned books and magazines, with one student naming Science Illustrated (\#13) and another the Curious Per (Nysgjerring Per) (\#08).

G. Attitudes toward coding. When asked about coding in particular, a few students related it to making games, perhaps grounding this perception on their participation in the 
specific workshop. Others described coding as "complicated" (\#11), "boring" (\#07), "not that interesting" (\#11; \#12; \#7), or "exhausting as it is difficult to understand everything" (\#22). Some recognized the link between coding and mathematics and the use of calculating in the coordination of the moving parts of the robots they had created. Scratch was perceived mostly as a positive experience, fun and easy to perform, and as often being easier than they initially thought it would be: "I thought it was going to be like very, very hard to do. But it was actually kind of easy" (\#4) and "I thought coding was easier than I was expecting. Before I thought that 'I wouldn't understand it', because it is so advanced, but it doesn't have to be advanced" (\#14). Nonetheless, some of them encountered difficulties when they tried to "figure out how to move the different things in the game" (\#11), to "find out how to insert sound" (\#11), and especially to work out "what to put in and how many seconds between each thing" (\#20). Those encountering such difficulties suggested that they needed more time to code the game as the instructions were not very clear or detailed ("if one had spent more time, it would have been easier" [\#24]; "you need to use time" [\#13]). Not having clear instructions in the manual resulted in them feeling stressed about coming up with an idea and creating a game in the second section of the workshop ("stressful at the end [.. .] because you need to finish it" [\#13]).

\section{Discussion}

Most of the students had medium and high science capital scores, indicating that our sample had a good level of scientific literacy that had potentially been developed through their engagement with plentiful, high-quality, science-related cultural and social resources (Archer et al., 2015). Additionally, their self-efficacy was highly correlated with their science capital, indicating that students who had been more exposed to science-related activities and contexts were more likely to have higher self-efficacy. Our findings are consistent with those of Archer et al. (2015) who also found that students with high science capital are significantly more confident in their science abilities than students with medium or low science capital. Moreover, in our study, students with higher previous experience with coding also had higher self-efficacy and higher science capital scores. This is expected because students, especially in making and coding contexts, both construct their own knowledge and develop a belief in their own capacities (self-efficacy) (Bandura et al., 2001; Wang, 2013).

Although previous research has reported gender differences in self-efficacy and confidence in CT and STEM-related subjects (Archer et al., 2015; Ardito et al., 2020), with boys reporting higher self-efficacy than girls, there was no significant difference between gender and self-efficacy or between gender and science capital in our study. This is probably related to most students in Norway (including in the region where our study was based) having equal access to science-related activities. It is also noteworthy that girls in Norway rank higher than boys in the mean score of science performance (PISA) (OECD, 2021); however, this was not reflected in our study regarding self-efficacy and science capital scores among both genders. Despite growing numbers of females in STEM fields in Norway, there have been national efforts and initiatives, such as IT camps and universities' "girls' days", that promote gender equality and inspire and attract girls to tech and STEM fields (Talks et al., 2019).

To gain a deeper understanding of these scores and the respective (or underpinned) values and beliefs, we turned to the qualitative data. In their descriptive accounts about the first thing that came to mind when hearing the word science, students named "doing science at school" and "science's potential and its contribution to society". At the same time, students often mentioned thinking of science as being the same as technology. In the Norwegian context, this is particularly relevant since technology and science are often used 


\section{ILS} $122,5 / 6$

together when referring to higher education or career perspectives (i.e. teknisknaturvitenskapelige). Nonetheless, this overlapping between technology and science has also been found in a UK study (Osborne and Collins, 2001), suggesting perhaps that this is a more widespread perception and highlighting the importance of the language and terminology that is employed in different contexts and cultures.

Regarding the resources that students are exposed to, a small number of students reported that they talked about science with others in their everyday lives, especially with members of their families ("we talk about plastic at home, because we try to use less plastic at home so we can help the Earth and try to be better examples" [\#12]; "our family can sit down to discuss a type of dish and end up discussing science [naturfag] and that kind of science [realfag] eventually" [\#11]). Talking about science and knowing people in a sciencerelated job were also scored the highest in the science capital questionnaire, underlining the importance of students' social context in reinforcing their social capital. Furthermore, three out of 22 mentioned books and magazines as a source of science-related information, while several referred to their participation in out-of-school science learning contexts, such as hiking and fishing as activities during which they learned about science. Nonetheless, none of them mentioned in their interviews or in the questionnaire that they were attending other coding clubs.

As enjoyment, interest and satisfaction are indicators of a positive experience that can lead to positive attitudes toward science studies (Bennett, 2001; George, 2003), knowing the factors that create and encourage such experiences is important. Based on the interview data set, the link between teachers, how they teach and students' attitudes toward science learning became evident. Students' perceptions about science were often linked to their perception of the teacher and how that teacher taught; they talked a lot about hands-on learning and how variety in methods and creativity in teaching contributed to their positive experience during science class and, thus, to their positive attitudes toward science. Specifically, they related their positive experiences to "doing things at the lab" where students reported that they had fun while learning by doing, making scientific concepts more accessible and understandable, a finding also reported by Osborne and Collins (2001). Students reported that they enjoyed more diverse teaching methods when learning science because these enhanced not only their enjoyment and interest but also their understanding and recollection of what they were being taught ("there is another way to learn again, which may make you remember better [...] [because] you have to actually do it with your own hands" [\#08]). This link between teachers and their teaching method in shaping students' interest in science has also been found by others (Ebenezer and Zoller, 1993; Osborne and Collins, 2001; Raved and Assaraf, 2011), who have argued that the use of creativity and fun in teaching has a positive impact on students' attitudes.

The ASPIRES project (Archer et al., 2015, 2017) reported that student attitudes to school science did not fully explain science aspirations, with approximately $15 \%$ of students aspiring to become a scientist expressing positive views toward school science. In our data set, we also identified that students often related their negative attitudes to science to their experiences with science at school. The participants offered examples of negative experiences as indicators of factors hindering their enjoyment and, thereby, their positive attitudes toward science. They talked a lot about "being taught while sitting and writing" as a negative experience, hinting at the use of traditional lecture-based instruction, in which the teacher stands in front of the students and teaches a planned and structured unit of material, as being boring and monotonous. Furthermore, the perceived overall difficulty of science at school contributed to shaping negative attitudes toward science, which aligns with Osborne and Collins's (2001) finding that students perceived many aspects of science uninteresting 
because they were "hard" or "difficult to understand". It is notable that despite students reporting medium and high self-efficacy when it came to their performance in science at school, they also reported a low desire to pursue a career in science. Claims such as "I don't see myself as a scientist" and "it is not for me" foregrounded the students' difficulty in imagining themselves pursuing such jobs and their development of negative dispositions toward science. This hesitation was often linked to the difficulty of learning about science at school, with students mentioning the time they needed to invest in learning about science in more depth. This is also in line with Osborne and Collins's (2001) finding that pupils in the UK perceived science as important but "not for me" and that the level of difficulty encountered in learning science often made them uninterested in the subject.

Finally, the existence of a "nerd identity" and stereotypical images of scientists (i.e. white male, with facial hair, working in a lab, wearing eyeglasses and a lab coat) seemed to alienate and limit potential participation in the field, with terms such as hacker, geek and nerd being used in a derogatory manner (Chambers, 1983; Davis et al., 2014; Fralick et al., 2009). Similar stereotypical images were mentioned in our data set, with scientists described as "crazy" and "nerdy", influencing the students negatively in imagining themselves as being a scientist and pursuing a career in science.

\subsection{Implications for research, theory and practice}

Our findings suggest that greater exposure of students to making and coding activities with relevant content in school or in out-of-school contexts can enhance their self-efficacy in STEM domains, thereby reinforcing their long-term interest in STEM fields. For example, this can be beneficial for sustaining girls' interest in science, as girls' views of science tend to become increasingly negative as they grow up [National Science Foundation (NSF), 2019]. Science at school is detrimental in the shaping of young adults' attitudes, so future revisions of the national curriculum in science should aim to allow more flexibility in choice of topics and to place more emphasis on the practical applications of science by adopting more handson approaches.

Nature was a recurrent theme, such as in relation to hiking trips and activities in nature like fishing or berry picking, both in our study and in that of Henriksen et al.'s (2014) research on Norwegian university students. This tendency might be specific to Norwegian society, which values outdoor life and nature, indicating the potential of promoting STEM through activities involving experiences in nature, such as by cooperating with associations like sports clubs and guides and scout associations, all of which are very common in Norway.

The need for creative teaching methods and active learning arose repeatedly in the interviews. Many students reported that their teachers failed to use varied teaching methods and that most lessons were taught as a lecture in which the teacher stood in front of the students and taught "dry" material, with the student's role being reduced to listening in class, repeating and preparing homework. Those responsible for teaching science need to consider diverse teaching methodologies, playful teaching and learning and hands-on activities, as these are important for framing students' attitudes to and experiences with science, as well as their self-esteem and their pleasure in science studies. The students mentioned experiments and their time in laboratories as learning environments that contributed to increasing their interest and curiosity, understanding the material, motivating thinking and creating a pleasant atmosphere in science classes. It was emphasized that interest and curiosity in science classes, created by a variety of teaching methods and means, are important not only for pleasure and a pleasant atmosphere but also for meaningful learning and the internalization of scientific subjects. 
ILS

$122,5 / 6$

With the interest in a science career diminishing with age, many teenagers find becoming a scientist unthinkable (Bennett and Hogarth, 2009; DeWitt et al., 2014). As most children aged 14/15 are in a process of making their future career choices (Munro and Elsom, 2000) while also being exposed to popular culture, including films, television, books and music, our findings identify a number of misconceptions that hinder their long-standing engagement with and aspirations to science-related careers. Specifically, we have identified stereotypes in popular culture (e.g. movies, books) about who can be a scientist. Moreover, stereotypes about the appearance of scientists are detrimental in the shaping of teenagers' attitudes toward science. Similarly, when asking girls and young women in Scandinavia to report challenges they might face when pursuing an education or a career in tech and STEM, the most frequently selected challenge was "stereotypes about what girls and boys can, or should do" (Talks et al., 2019). In the case of Norway, Sjøberg (2002) found that when children were asked to draw a mathematician or a scientist, girls drew men more often than women, while boys almost universally drew men, often wearing a lab coat.

With children being exposed to gender stereotypes from a very early age (Bian $e t$ al., 2017), which include stereotypes of STEM as a "masculine" field in Norway (Schreiner, 2008), these widespread stereotypes and misconceptions about what science is and who can be a scientist seem to contribute to the aforementioned age-related decline in pursuing science-related careers. Such stereotypes and their negative impact on promoting a positive attitude toward science indicate the importance of encouraging a more realistically grounded science identity among students. Educators need to make more overt links between science and jobs involving science, because this connection is not apparent to many students. A couple of suggestions are to organize events designed to stimulate interest and inform students about science and engineering at the age of 10/11 by leveraging popular culture that is familiar to them (e.g. music); and to enable mentoring by and meeting with past students who are working in STEM-related fields (e.g. via ambassador programs/ events). School counselors in Norway "have little or no formal education in this area" (Buland and Mathiesen, 2008, p. 33, our translation), which might have an impact on the links young adults make regarding science careers. As school settings are important in forming attitudes toward science, having school counsellors with a science background would result in better informed decisions when students reach out to them.

By broadening their ideas about the activities and skills needed to work as a scientist and by providing clearer links between a career in science and the science curriculum, we can facilitate students to "see themselves as scientists" or as being capable of pursuing a career in science and coding (i.e. skills acquired and required).

\subsection{Limitations}

Our study is limited by the design of the activity, some logistical and practical constraints (i.e. one-day activity), and the particularities of the school and classes that we worked with, as the students' socioeconomic background is likely to be similar among those coming from the same school. Including a group of students from different schools and backgrounds might have offered more diverse self-efficacy and science capital. At the same time, as the students' experience of school science and science teaching is a key factor in shaping their attitudes toward science, a longitudinal qualitative study would enable exploration of the ways in which varied resources, dispositions and ways of being/talking/thinking about science within the learning settings (i.e. classrooms and Kodeløypa) are recognized, valued and sustained over time by the teachers, facilitators and so on (Carlone et al., 2014; George, 2003). Lastly, collecting and analyzing both descriptive and explanatory data generated an 
extensive data set, which, in turn, imposed an equally extensive workload for analysis and reporting.

Lens of science capital

\section{Conclusions}

Based on our findings, we argue that science capital can serve as a useful lens to capture aspects of students' previous and current experiences with science learning in and out of school. This study contributes to the line of research that combines qualitative and quantitative methods to identify and explore young adults' attitudes. By combining different methods and tools, our research enabled gathering both descriptive and explanatory data on students' attitudes to science. Using interviews when exploring attitudes has been an uncommon practice when exploring attitudes (Osborne $e t$ al., 2003), but they allowed us to move away from "fixed-response inventories [...] [and] an emphasis on descriptions of the problem" to pay more attention to "possible explanations" (Bennett and Hogarth, 2009, p. 1977).

By complementing the science capital questionnaire with data from the interviews, we identified several factors that have informed, and perhaps continue to inform, students' attitudes both to science and to themselves as being "sciency". When looking more closely at the dimensions of science capital, our findings suggest that what happens at school is of primary importance in shaping and fostering an interest in science: the school experience shapes students' attitudes to and beliefs about science learning in and out of school, as well as their aspirations to follow a science-related career path. This study adds to the growing evidence that attitudes to science outside school are more positive than attitudes to school science, and that experiences of school science between the ages of 11 and 14 years are crucial in shaping students' attitudes and subsequent behaviors in relation to subject choice. More research is needed to identify how these aspects identified in our data set change over time and to identify aspects of science teaching that make school science engaging for students.

\section{References}

Archer, L., Dawson, E., DeWitt, J., Godec, S., King, H., Mau, A., Nomikou, E. and Seakins, A. (2017), "Killing curiosity? An analysis of celebrated identity performances among teachers and students in nine London secondary science classrooms", Science Education, Vol. 101 No. 5, pp. 741-764.

Archer, L., Dawson, E., DeWitt, J., Seakins, A. and Wong, B. (2015), “'Science capital': a conceptual, methodological, and empirical argument for extending Bourdieusian notions of capital beyond the arts", Journal of Research in Science Teaching, Vol. 52 No. 7, pp. 922-948.

Ardito, G., Czerkawski, B. and Scollins, L. (2020), "Learning computational thinking together: effects of gender differences in collaborative middle school robotics program", TechTrends, Vol. 64 No. 3 , pp. 373-387.

Bandura, A. (1977), "Self-efficacy: toward a unifying theory of behavioral change", Psychological Review, Vol. 84 No. 2, pp. 191-215.

Bandura, A. (1997), Self-efficacy: The exercise of control. W H Freeman/Times Books/Henry Holt and $\mathrm{Co}$.

Bandura, A., Barbaranelli, C., Caprara, G.V. and Pastorelli, C. (2001), "Self-efficacy beliefs as shapers of children's aspirations and career trajectories”, Child Development, Vol. 72 No. 1, pp. 187-206, doi: 10.1111/1467-8624.00273.

Barton, A.C., Tan, E. and Greenberg, D. (2017), "The makerspace movement: sites of possibilities for equitable opportunities to engage underrepresented youth in STEM", Teachers College Record, Vol. 119 No. 7, pp. 1-44. 


\section{ILS $122,5 / 6$}

Bennett, J. (2001), "Science with attitude: the perennial issues of pupils' responses to science", School Science Review, Vol. 82, pp. 59-67.

Bennett, J. and Hogarth, S. (2009), "Would you want to talk to a scientist at a party? High school students' attitudes to school science and to science", International Journal of Science Education, Vol. 31 No. 14, pp. 1975-1998, doi: 10.1080/09500690802425581.

Bian, L., Leslie, S.J. and Cimpian, A. (2017), “Gender stereotypes about intellectual ability emerge early and influence children's interests”, Science, Vol. 355 No. 6323, pp. 389-391.

Bonner, D. and Dorneich, M. (2016), "Developing game-based learning requirements to increase female middle school students' interest in computer science", Proceedings of the Human Factors and Ergonomics Society Annual Meeting, Vol. 60 No. 1, pp. 380-384.

Buland, T. and Mathiesen, I.H. (2008), "Gode råd? En kunnskapsoversikt over feltet yrkes- og utdanningsrådgivning, sosialpedagogisk rådgivning og oppfølgingstjeneste i norsk skole" ('good advice? A knowledge overview of the field of vocational and educational counseling, social pedagogical counseling and follow-up service in Norwegian schools')", Report, SINTEF Technology and Society, Trondheim.

Carlone, H.B., Scott, C.M. and Lowder, C. (2014), "Becoming (less) scientific: a longitudinal study of students' identity work from elementary to middle school science", Journal of Research in Science Teaching, Vol. 51 No. 7, pp. 836-869.

Chambers, D.W. (1983), "Stereotypic images of the scientist: the draw-a-scientist test", Science Education, Vol. 67 No. 2, pp. 255-265.

Chu, S.L., Angello, G., Saenz, M. and Quek, F. (2017a), "Fun in making: understanding the experience of fun and learning through curriculum-based making in the elementary school classroom", Entertainment Computing, Vol. 18, pp. 31-40.

Chu, S.L., Schlegel, R., Quek, F., Christy, A. and Chen, K. (2017b), "I make, therefore I am': the effects of curriculum-aligned making on children's self-identity", Proceedings of the 2017 CHI Conference on Human Factors in Computing Systems, Association for Computing Machinery, New York, NY, pp. 109-120.

Cohen, L., Manion, L. and Morrison, K. (2011), Research Methods in Education, Routledge, London.

COMnPLAY Science (2021), "D1.2 COMnPLAY science research instruments and tools", report, available at: https://comnplayscience.eu/wp-content/uploads/2021/02/D1.2.pdf (accessed 20 February 2021).

Clarke, V., Braun, V., Terry, G. and Hayfield, N. (2019), “Thematic analysis”, in Liamputtong, P. (Ed.), Handbook of Research Methods in Health and Social Sciences, Springer, pp. 843-860.

Davis, D., Yuen, T. and Berland, M. (2014), "Multiple case study of nerd identity in a CS1 class", Proceedings of the 45th ACM Technical Symposium on Computer Science Education (SIGCSE '14), Association for Computing Machinery, New York, NY, pp. 325-330, doi: 10.1145/ 2538862.2538960.

DeWitt, J., Archer, L. and Mau, A. (2016), "Dimensions of science capital: exploring its potential for understanding students' science participation”, International Journal of Science Education, Vol. 38 No. 16, pp. 2431-2449.

DeWitt, J., Archer, L. and Osborne, J. (2014), "Science-related aspirations across the primary-secondary divide: evidence from two surveys in England", International Journal of Science Education, Vol. 36 No. 10, pp. 1609-1629, doi: 10.1080/09500693.2013.871659.

Ebenezer, J.V. and Zoller, U. (1993), "Grade 10 students' perceptions of and attitudes toward science teaching and school science”, Journal of Research in Science Teaching, Vol. 30 No. 2, pp. 175-186.

Fralick, B., Kearn, J., Thompson, S. and Lyons, J. (2009), "How do middle schoolers draw engineers and scientists?", Journal of Science Education and Technology, Vol. 18 No. 1, pp. 60-73. 
George, R. (2003), "Growth in students' attitudes about the utility of science over the middle and high school years: evidence from the longitudinal study of American youth", Journal of Science Education and Technology, Vol. 12 No. 4, pp. 439-448.

George, R. (2006), "A cross-domain analysis of change in students' attitudes toward science and attitudes about the utility of science", International Journal of Science Education, Vol. 28 No. 6, pp. 571-589, doi: 10.1080/09500690500338755.

Giannakos, M.N. and Jaccheri, L. (2018), "From players to makers: an empirical examination of factors that affect creative game development", International Journal of Child-Computer Interaction, Vol. 18, pp. 27-36.

Godec, S., King, H. and Archer, L. (2017), The Science Capital Teaching Approach: Engaging Students with Science, Promoting Social Justice, University College London, London.

Halverson, E.R. and Sheridan, K. (2014), "The maker movement in education”, Harvard Educational Review, Vol. 84 No. 4, pp. 495-504.

Henriksen, E.K., Jensen, F. and Sjaastad, J. (2014), "The role of out-of-school experiences and targeted recruitment efforts in Norwegian science and technology students' educational choice", International Journal of Science Education, Part B, Vol. 5 No. 3, pp. 203-222.

Kafai, Y.B., Fields, D.A. and Searle, K.A. (2014), "Electronic textiles as disruptive designs: supporting and challenging maker activities in schools", Harvard Educational Review, Vol. 84 No. 4, pp. 532-556.

Kafai, Y.B. and Peppler, K.A. (2014), "Transparency reconsidered: creative, critical and connected making with e-textiles", in Boaler, M. and Ratto, M. (Eds), DIY Citizenship: Participatory Practices of Politics, Culture and Media, The MIT Press, Cambridge, MA, pp. 300-310.

Martin, L. (2015), "The promise of the maker movement for education", Journal of Pre-College Engineering Education Research (J-PEER), Vol. 5 No. 1, pp. 30-39.

Munro, M. and Elsom, D. (2000), "Choosing science at 16: the influence of science teachers and careers advisers on students' decisions about science subjects and science and technology careers", CRAC, Cambridge, available at: https://files.eric.ed.gov/fulltext/ED448334.pdf

Nietfeld, J.L., Cao, L. and Osborne, J.W. (2006), "The effect of distributed monitoring exercises and feedback on performance, monitoring accuracy, and self-efficacy", Metacognition and Learning, Vol. 1 No. 2, pp. 159-179.

National Science Foundation (NSF) (2019), "Women, minorities, and persons with disabilities in science and engineering", special report, NSF and National Center for Science and Engineering Statistics, Arlington, VA, available at: https://ncses.nsf.gov/pubs/nsf19304/digest/about-thisreport

OECD (2021), "Science performance (PISA) (indicator)", doi: 10.1787/91952204-en (accessed 2 March 2021).

Osborne, J. and Collins, S. (2001), "Pupils' views of the role and value of the science curriculum", International Journal of Science Education, Vol. 23 No. 5, pp. 441-467.

Osborne, J., Simon, S. and Collins, S. (2003), “Attitudes towards science: a review of the literature and its implications”, International Journal of Science Education, Vol. 25 No. 9, pp. 1049-1079.

Papavlasopoulou, S., Giannakos, M.N. and Jaccheri, L. (2017), "Empirical studies on the maker movement, a promising approach to learning: a literature review", Entertainment Computing, Vol. 18, pp. 57-78.

Papert, S. (1980), Mindstorms: Children, Computers, and Powerful Ideas, Basic Books, New York, NY.

Peppler, K., Halverson, E.R. and Kafai, Y. (2016), Makeology: Makerspaces as Learning Environments, Routledge, New York, NY.

Raved, L. and Assaraf, O.B.Z. (2011), "Attitudes towards science learning among 10th-grade students: a qualitative look", International Journal of Science Education, Vol. 33 No. 9, pp. 1219-1243. 


\section{ILS $122,5 / 6$}

Regan, E. and DeWitt, J. (2015), "Attitudes, interest and factors influencing STEM enrolment behaviour: an overview of relevant literature", in Henriksen, E., Dillon, J. and Ryder, J. (Eds), Understanding Student Participation and Choice in Science and Technology Education, Springer, Dordrecht, pp. 63-88.

Schlegel, R.J., Chu, S.L., Chen, K., Deuermeyer, E., Christy, A.G. and Quek, F. (2019), "Making in the classroom: longitudinal evidence of increases in self-efficacy and STEM possible selves over time", Computers and Education, Vol. 142, p. 103637.

Schreiner, C. (2008), "Noen realist som passer for meg? Ungdoms valg av utdanning og yrke" ('anything in the science field that fits me? Young people's choice of education and occupation')", Kimen, Vol. 1, available at: www.naturfagsenteret.no/c1405591/binfil/download2.php?tid=1509697 (accessed 2 March 2021).

Sheridan, K., Halverson, E.R., Litts, B., Brahms, L., Jacobs-Priebe, L. and Owens, T. (2014), "Learning in the making: a comparative case study of three makerspaces", Harvard Educational Review, Vol. 84 No. 4, pp. 505-531.

Sjøberg, S. (2002), Science for the Children? Report from the Science and Scientists Project, a CrossCultural Study of Factors of Relevance for the Teaching and Learning of Science and Technology, Department of Teacher Education and School Development, University of Oslo.

Stoet, G. and Geary, D.C. (2018), "The gender equality paradox in STEM education”, Psychological Science, Vol. 29 No. 4, pp. 581-593.

Talks, I., Edvinsson, I. and Birchall, J. (2019), Programmed out - the Gender Gap in Technology in Scandinavia: What Are Successful Ways to Get More Girls into Tech in Scandinavia?, Plan International, Norway.

Tytler, R. and Osborne, J. (2012), "Student attitudes and aspirations towards science", in Fraser, B.J., Tobin, K.G. and McRobbie, C.J. (Eds), Second International Handbook of Science Education, Springer, Dordrecht, Netherlands, pp. 597-625, doi: 10.1007/978-1-4020-9041-7_41.

Vossoughi, S. and Bevan, B. (2014), "Making and tinkering: a review of the literature", Commissioned Paper for Successful Out-of-School STEM Learning: A Consensus Study, Board on Science Education, National Research Council, Washington, DC, available at: https:/sites. nationalacademies.org/cs/groups/dbassesite/documents/webpage/dbasse_089888.pdf

Wang, X. (2013), "Why students choose STEM majors: motivation, high school learning, and postsecondary context of support", American Educational Research Journal, Vol. 50 No. 5 , pp. 1081-1121.

Yang, H.-L. and Cheng, H.-H. (2009), "Creative self-efficacy and its factors: an empirical study of information system analysts and programmers", Computers in Human Behavior, Vol. 25 No. 2 , pp. $429-438$. 
Appendix 1. The questionnaire used along with the score by which science capital was calculated (i.e. the red number in parentheses for each question)

1. Before you begin, do you take part in an event or workshop?

2. Boy or girl?

3. How old are you?

4. What is your grade?

5. Did you have any idea about programming before this workshop?

Not at all Very much

$$
\begin{array}{llllllll}
1 & 2 & 3 & 4 & 5 & 6 & 7
\end{array}
$$

6. How many workshops (e.g., on Scratch, Alice, Lego Robots, Python) have you participated in before?

The answers were coded for the data analysis as the numbers written in parentheses
a. None (1)
b. $1(2)$
c. $2-3(3)$
d. $4-5(4)$
e. 6 or more (5)

Science capital questions: Please note that the final score for each child was obtained by dividing the initial score by the number of questions answered and not by the total number of questions. The scores for each answer are placed in the parentheses. Responses such as "I don't know" or "I am not sure" were recorded as not responding to that question, and the total score was then divided by the total number of questions answered. We scored questions 5 and 6 together using the following schema: if the answer was $5 b$ or $5 c$, then questions 5 and 6 were ignored. For question 6 , if someone answered more than one, we took the average.

1. How much do you agree with the following? It is useful to know about science in your daily life and in the future.
a. Yes, I strongly agree (2)
b. Yes, I agree (1)
c. I am undecided $(0)$
d. No, I disagree (-1)
e. No, I strongly disagree (-2)

(continued) 
ILS

$122,5 / 6$

336

2. How important do your parents/guardians think learning science will be for your future?

a. Yes, very important (2)

b. Yes, moderately important (1)

c. They don't have an opinion either way (0)

d. No, of little importance (-1)

e. No, not important at all (-2)

f. I don't know

3. Have your teachers specifically encouraged you to continue studying science when you are older?
a. A great deal (2)
b. Some (1)
c. A little (-1)
d. Not at all (-2)
e. I am not sure

4. How useful will science knowledge and skills be in helping you get many different sorts of job?
a. Very useful (2)
b. Moderately useful (1)
c. Of average use (0)
d. Not very useful (-1)
e. Not useful at all (-2)

5. Do you know someone who works in a science-related job?
a. Yes
b. No
c. I don't know

6. Who do you know who works in a science-related job? (tick all that apply)
a. Parent/guardian (2)
b. Member of wider family (1)
c. Friend's parent (1)
d. Neighbor (1)
e. Other (1)
f. No one 
7. When you're not at school, do you talk about science (including coding and making) with other people?
a. Frequently (2)
b. Occasionally (1)
c. Rarely (0)
d. Very rarely $(-1)$
e. $\quad$ Never $(-2)$

8. If you do talk about science outside of school, who do you talk with? (tick all that apply) ( 0.5 for each response)
a. Parents/guardians
b. Friends
c. Brothers/sisters
d. Wider family (aunts, uncles, grandparents)
e. Community members
f. Others

9. How often do you read science books or magazines, or look up science content online?
a. All the time (at least every other day) (2)
b. Regularly (at least once a week) (1)
c. Sometimes (about once a month) (0)
d. Seldom (a couple of times a year) $(-1)$
e. Never (-2)

10. How often do you go to museums or science centers or zoos/aquaria?
a. Regularly (at least once a month) (2)
b. Occasionally (at least once a term) (1)
c. Sometimes (about once a year) (0)
d. Rarely (at least once every other year) $(-1)$
e. Never (-2)

11. How often do you go to a coding club/workshop, making club/workshop, or science club/workshop?
a. Regularly (at least once a month) (2)
b. Occasionally (at least once a term) (1)
c. Sometimes (about once a year) ( 0 )
d. Rarely (at least once every other year) $(-1)$
e. Never (-2) 


\section{ILS}

$122,5 / 6$

338

12. How are you doing in science lessons at school?
a. I'm doing really well! (2)
b. I'm doing well! (1)
c. I'm acceptable! (0)
d. I'm not doing very well! (-1)
e. I'm doing really badly! (-2)
f. I don't know!

\section{Self-efficacy questions:}

1. I am sure that I can learn science.

$\begin{array}{llllllll}1 & 2 & 3 & 4 & 5 & 6 & 7\end{array}$

Not at all

Very much

2. I can get a good grade in science.

$\begin{array}{llllllll}1 & 2 & 3 & 4 & 5 & 6 & 7\end{array}$

Not at all

Very much

3. I am sure I could do middle-school science.

$\begin{array}{llllllll}1 & 2 & 3 & 4 & 5 & 6 & 7\end{array}$

Not at all

Very much

4. I have a lot of self-confidence when it comes to science.

$\begin{array}{lllllllll}1 & 2 & 3 & 4 & 5 & 6 & 7\end{array}$

Not at all

Very much

5. I am not the type to do well in science.

$\begin{array}{lllllllll}1 & 2 & 3 & 4 & 5 & 6 & 7\end{array}$

Not at all

Very much

6. It takes me a long time to learn new things in science.
1
2
3
4
5
6
7

Not at all

Very much

7. Even before I begin a new topic in science, I feel confident I will be able to understand it.
1
12
3
4
5
6
7

Not at all

Very much

8. I think I have good skills and strategies to learn science.

$\begin{array}{llllll}1 & 2 & 3 & 4 & 5\end{array}$

5

6

7

Not at all

Very much 
(1) What is the meaning of science for you? When you hear the word "science", what comes to your mind?

(2) How would you describe your feelings and beliefs about science?

(3) Do you think that learning about science is important?

(4) Can you tell me why/why not?

(5) Do you think that learning about science is fun?

(6) Can you tell me why/why not?

(7) How do you feel about studying science?

(8) What makes you interested in science?

(9) What kinds of science are you most interested in?

(10) Apart from school, are you learning and talking about science in other places?

(11) Do you talk about science with others? If yes, with whom?

(12) When you hear the word "scientist", what comes to your mind?

(13) Do your ideas about scientists come from personal experience? If not, where do they come from?

(14) Do you think of scientists as someone like you?

(15) Do you think of yourself as someone who is good at science?

(16) How well do you think you are doing at science, both at school and elsewhere?

(17) Can you tell me why you think so?

(18) What kind of science activities do you like to do?

(19) What do you think you learned today?

(20) Did the workshop change your opinion regarding computer science/coding/science in general?

(21) Do you think that your activity is related to any other subjects like math or physics? If yes, how?

(22) How do you think you can use coding in the future?

(23) Did coding increase your interest in science?

(24) Which part of today's workshop did you like more?

(25) Do you think that coding is interesting?

(26) Was coding/creating the game helpful regarding your coding skills?

(27) Could you mention some difficult or easy parts of this experience? 


\section{ILS \\ $122,5 / 6$}

Appendix 3. Variables and statistical results

Questions
5. Did you have any idea about programming before this
workshop?

6. How many workshops (e.g., on Scratch, Alice, Lego

Robots, Python) have you participated in before?

Science capital questions

1. How much do you agree with the following? It is useful

to know about science in your daily life and in the future.

2. How important do your parents/guardians think

learning science will be for your future?

3. Have your teachers specifically encouraged you to continue studying science when you are older?

4. How useful will science knowledge and skills be in helping you get many different sorts of job?

5 and 6 . Do you know someone who works in a sciencerelated job? and Who do you know who works in a science-related job?

7. When you're not at school, do you talk about science (including coding and making) with other people?

\section{Table A1.}

Questions, their respective variable's name, mean and standard deviation (the number of the question is the same as the one in the questionnaire presented in Appendix 1)
8. If you do talk about science outside of school, whom do you talk with?

9. How often do you read science books or magazines, or look up science content online?

10. How often do you go to museums, or science centers, or zoos/aquaria?

11. How often do you go to a coding club/workshop, making club/workshop, or science club/workshop?

12. How are you doing in science lessons at school?

Total score of science capital

Self-efficacy (construct)

\begin{tabular}{lrc} 
Variable's acronym/name & Mean & SD \\
\hline Prior coding experience & 2.17 & 0.97 \\
Previous attendance & 1.6 & 0.97
\end{tabular}

Useful to know about science

$1.05 \quad 0.71$

Important for the future

$0.98 \quad 0.81$

Teachers' encouragement

$-0.52 \quad 1.38$

Science knowledge skills

$0.70 \quad 1.09$

useful for the future

If and who you know in a

$1.22 \quad 0.39$

science job

Talk about science at school

$-0.25 \quad 1.31$

Who do you talk about science

$1.29 \quad 1.47$

with?

How often do you read science- $\quad-0.91 \quad 1.14$

related materials?

How often do you go to

museums, aquaria etc.?

How often do you go to coding $\quad-1.70 \quad 0.59$

clubs or similar activities?

How are you doing in science $\quad 0.62 \quad 0.82$

lessons at school?

Total science capital score

Self-efficacy

\section{Corresponding author}

Dimitra Christidou can be contacted at: dimitra.christidou@ntnu.no

For instructions on how to order reprints of this article, please visit our website: 